\title{
Review
}

\section{Multifaceted highly targeted sequential multidrug treatment of early ambulatory high-risk SARS-CoV-2 infection (COVID-19)}

Peter A. McCullough ${ }^{1} * \oplus^{\circ}$, Paul E. Alexander ${ }^{2}$, Robin Armstrong ${ }^{3}$, Cristian Arvinte ${ }^{4}$, Alan F. Bain ${ }^{5}$, Richard P. Bartlett ${ }^{6}$,

Robert L. Berkowitz ${ }^{\oplus}$, Andrew C. Berry ${ }^{8}$, , Thomas J. Borody9 ${ }^{9}$ Joseph H. Brewer ${ }^{10}$, Adam M. Brufsky ${ }^{11} \mathcal{C}^{1}$, Teryn Clarke ${ }^{12}$,

Roland Derwand ${ }^{13}$, Alieta Eck ${ }^{14}$, John Eck ${ }^{14}$, Richard A. Eisner ${ }^{15}$, George C. Fareed ${ }^{16}$, Angelina Farella ${ }^{17}$, Silvia N. S. Fonseca ${ }^{18}$,

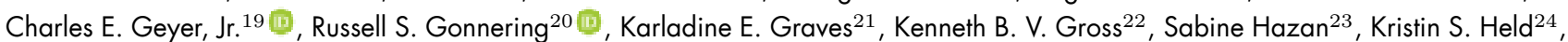
H. Thomas Hight ${ }^{25}$, Stella Immanuel ${ }^{26}$, Michael M. Jacobs 27 , Joseph A. Ladapo ${ }^{28}$, Lionel H. Lee ${ }^{29}$, John Littell ${ }^{30}$, Ivette Lozano ${ }^{31}$,

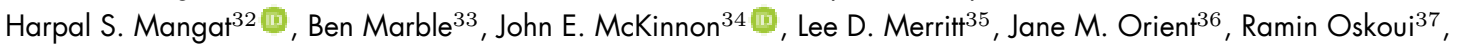

Donald C. Pompan ${ }^{38}$, Brian C. Procter ${ }^{39}$, Chad Prodromos ${ }^{40}$, Juliana Cepelowicz Rajter ${ }^{41}$ (C), Jean-Jacques Rajter ${ }^{41}$ (C),

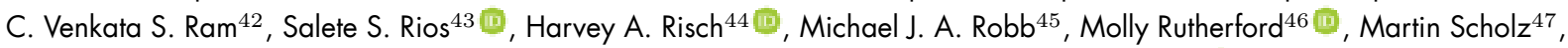
Marilyn M. Singleton ${ }^{48}$, James A. Tumlin ${ }^{49}$, Brian M. Tyson ${ }^{50}$, Richard G. Urso ${ }^{51}$, Kelly Victory ${ }^{52}$ (D) Elizabeth Lee Vliet ${ }^{53}$, Craig M. Wax ${ }^{54}$, Alexandre G. Wolkoff55 ${ }^{\circ}$, Vicki Wooll ${ }^{56}$ and Vladimir Zelenko ${ }^{57}$

${ }^{1}$ Baylor University Medical Center, Baylor Heart and Vascular Institute, Baylor Jack and Jane Hamilton Heart and Vascular Hospital, Dallas, 75226, TX, USA

${ }^{2}$ Department of Health Research Methods, Evidence and Impact, McMaster University, Hamilton, L8S 4L8, Ontario, Canada

${ }^{3}$ Armstrong Medical Group, Texas City, 75510, TX, USA

${ }^{4}$ North Suburban Medical Center and Vibra Hospital, Thornton, 80229, Colorado, USA

${ }^{5}$ Chicago Health and Wellness Alliance, Chicago, 60603, IL, USA

${ }^{6}$ Recipient of the Texas HHS Meritorious Service Award, 78751, Texas, USA

${ }^{7}$ PianoPsych, LLC, Natick, 01760, MA, USA

${ }^{8}$ Division of Gastroenterology, Department of Medicine, Larkin Community Hospital, S. Miami, 33143 , FL, USA

${ }^{9}$ Centre for Digestive Diseases, Five Dock, 2046, NSW, Australia

${ }^{10}$ Infectious Diseases, St. Luke's Hospital, Kansas City, 64111 , MO, USA

${ }^{11}$ University of Pittsburgh, Department of Medicine, Pittsburgh, 15213, PA, USA

${ }^{12}$ Clarke Neurology, Newport Beach, 92660, CA, USA

${ }^{13}$ Alexion Pharma Germany GmbH, 80687, Munich, Germany

${ }^{14}$ Affordable Health, Inc., Piscataway, 08854, NJ, USA

${ }^{15}$ Eisner Laser Center, Macon, 31210, GA, USA

${ }^{16}$ Pioneers Medical Center, Brawley, 92227, CA, USA

${ }^{17}$ Privia Medical Group, Webster, 24510, TX, USA

${ }^{18}$ Hapvida HMO, Ribeirão Preto, 14015-130, SP, Brazil

19 Houston Methodist Cancer Center, Houston, 77030, TX, USA

${ }^{20}$ The Medical College Of Wisconsin, Milwaukee, 53226, WI, USA

${ }^{21}$ Personal Healthcare Network, Kansas City, 641 16, MO, USA

${ }^{22}$ Fusion Clinical Multimedia, Inc., Philadelphia, 19019, PA, USA

${ }^{23}$ Ventura Clinical Trials, PROGENABIOME, Malibu Specialty Center, Ventura, 93003, CA, USA

${ }^{24}$ Stone Oak Ophthalmology, Immediate Past President, Association of American Physicians and Surgeons, San Antonio, 78258, TX, USA

${ }^{25}$ Cardiosound, Atlanta, 30342, GA, USA

${ }^{26}$ Rehoboth Medical Center, Houston, 77083, TX, USA

${ }_{27}$ Complex Primary Care Medicine, Pensacola, 32507, FL, USA

28 University of California Los Angeles, Los Angeles, 90095, CA, USA

${ }^{29}$ Emergency Medicine, Phoenix, 85016, AZ, USA

${ }^{30}$ Family Medicine, Kissimmee, 34741, FL, USA

${ }^{31}$ Lozano Medical Clinic, Dallas, 75218, TX, USA

${ }^{32}$ Howard University College of Medicine, Mangat and Kaur, Inc., Germantown, 20876, MD, USA

33 President, MyFreeDoctor.com Pensacola Beach, 3256, FL, USA

${ }^{34}$ Department of Medicine, Henry Ford Hospital, Wayne State University School of Medicine, Detroit, 48202, MI, USA

${ }^{35}$ Orthopaedic and Spinal Surgery, Private Practice, Omaha, 68135, NE, USA

${ }^{36}$ Internal Medicine, Executive Director, Association of American Physicians and Surgeons, Tucson, 85716, AZ, USA

${ }^{37}$ Foxhall Cardiology, PC, Washington, 20016, DC, USA

${ }^{38}$ Orthopedic Surgery, Salinas, 93907, CA, USA

${ }^{39}$ McKinney Family Medicine, McKinney, 75070, TX, USA

40 Illinois Sports Medicine and Orthopaedic Center, Glenville, 60025, IL, USA

${ }^{41}$ Pulmonary and Sleep Consultants, Ft. Lauderdale, 33316, FL, USA

${ }^{42}$ MediCiti Medical College, 500005, Hyderabad, India

${ }^{43}$ University of Brasília, Brasilia, 70910-900, DF, Brazil

${ }^{44}$ Department of Chronic Disease Epidemiology, Yale School of Public Health, New Haven, 06510, CT, USA

${ }^{45}$ Robb Oto-Neurology Clinic, Phoenix, 85012, AZ, USA

${ }^{46}$ Bluegrass Family Wellness, Crestwood, 40014, KY, USA

${ }^{47}$ Heinrich Heine University, Düsseldorf, 40225, Germany

${ }^{48}$ Past Pres. Association of American Physicians and Surgeons, Tucson, 85716, AZ, USA

${ }^{49}$ NephroNet Clinical Trials Consortium, Buford, 30518, GA, USA

${ }^{50}$ All Valley Urgent Care, El Centro, 92243, CA, USA

${ }^{51}$ Houston Eye Associates, Houston, 77025, TX, USA

${ }^{52}$ Victory Health, LLC., 80487, Colorado, USA

${ }^{53}$ Vive Life Center, 85728, Arizona \& Texas, USA

${ }^{54}$ Family Medicine, Mullica Hill, 08062, NJ, USA

${ }^{55}$ CMO Emergency Hapvida Saude, HMO, Fortaleza, 60140-061, CE, Brazil

${ }^{56}$ National Healthcare Coalition, Family Medicine, Eagle, 83616, ID, USA

${ }^{57}$ Affiliate Physician, Columbia University Irving Medical Center, New York City, 10032, NY, USA

*Correspondence: peteramccullough@gmail.com (Peter A. McCullough)

DOI: $10.31083 /$ i.rcm.2020.04.264

This is an open access article under the CC BY 4.0 license (https://creativecommons.org/licenses/by/4.0/).

Rev. Cardiovasc. Med. 2020 vol. 21(4), 517-530

()2020 McCullough et al. Published by IMR Press. 
The SARS-CoV-2 virus spreading across the world has led to surges of COVID-19 illness, hospitalizations, and death. The complex and multifaceted pathophysiology of life-threatening COVID-19 illness including viral mediated organ damage, cytokine storm, and thrombosis warrants early interventions to address all components of the devastating illness. In countries where therapeutic nihilism is prevalent, patients endure escalating symptoms and without early treatment can succumb to delayed in-hospital care and death. Prompt early initiation of sequenced multidrug therapy (SMDT) is a widely and currently available solution to stem the tide of hospitalizations and death. A multipronged therapeutic approach includes 1) adjuvant nutraceuticals, 2) combination intracellular anti-infective therapy, 3) inhaled/oral corticosteroids, 4) antiplatelet agents/anticoagulants, 5) supportive care including supplemental oxygen, monitoring, and telemedicine. Randomized trials of individual, novel oral therapies have not delivered tools for physicians to combat the pandemic in practice. No single therapeutic option thus far has been entirely effective and therefore a combination is required at this time. An urgent immediate pivot from single drug to SMDT regimens should be employed as a critical strategy to deal with the large numbers of acute COVID-19 patients with the aim of reducing the intensity and duration of symptoms and avoiding hospitalization and death.

\section{Keywords}

SARS-CoV-2; COVID-19; hospitalization; mortality; ambulatory treatment; anti-infective; anti-inflammatory; antiviral; corticosteroid; antiplatelet agent; anticoagulant; sequenced multidrug therapy

The pandemic of SARS-CoV-2 (COVID-19) is advancing unabated across the world with each country and region developing distinct epidemiologic patterns in terms of frequency, hospitalization, and death. There are four pillars to an effective pandemic response: 1) contagion control, 2) early treatment, 3) hospitalization, and 4) vaccination to assist with herd immunity (Fig. 1). Additionally, when feasible, prophylaxis could be viewed as an additional pillar since it works to reduce the spread as well as incidence of acute illness. Many countries have operationalized all four pillars including the second pillar of early home-based treatment with distributed medication kits of generic medications and supplements as shown in Table 1. In the US, Canada, United Kingdom, Western European Union, Australia, and some South American Countries there has been three major areas of focus for pandemic response: 1) containment of the spread of infection (masking, social distancing, etc., 2) late hospitalization and delayed treatments (remdesivir, convalescent plasma, antiviral antibodies), and 3) vaccine development (Bhimraj et al., 2020; COVID-19 Treatment Guidelines, 2020). Thus the missing pillar of pandemic response is early home-based treatment (as seen in Fig. 1).

The current three-pronged approach has missed the predominant opportunity to reduce hospitalization and death given the practice of directing patients to self-isolation at home. Early sequential multidrug therapy (SMDT) is the only currently available method by which hospitalizations and possibly death could be reduced in the short term (McCullough et al., 2020a). Most COVID-
19 patients with progressive symptoms who arrive to hospital by emergency medical services do not require intubation or pressors initially in the field (Yang et al., 2020). Once hospitalized, if oxygen is required the mortality rate rises to $\sim 12 \%$ (Palazzuoli et al., 2020). Approximately one quarter require mechanical ventil ation, advanced circulatory support, or renal replacement therapy and in that group the mortality exceeds $25 \%$ (S. Gupta et al., 2020a,b). Our observations suggest a majority of hospitalizations could be avoided with a first treat-at-home strategy with appropriate telemedicine monitoring and access to oxygen and therapeutics. Patients will have the best chance of therapeutic gain when trea ted before there is significant progression of disease (Argenziano et al., 2020; McCullough et al., 2020b; Rhodes et al., 2017).

The majority serious viral infections require early treatment with multiple agents and this approach has not been applied in trials of COVID-19 sponsored by governments or industry. Since COVID-19 syndrome is characterized by early exponential viral proliferation, cytokine-mediated organ damage and dysfunction, and endothelial injury with proximal platelet aggregation with thrombosis, (Fig. 2) it is not realistic to assume a single drug or antibody could comprehensively handle all of these manifestations. At this time there are no reports of conclusive randomized trials of oral ambulatory therapy for COVID-19 and none are expected in the short term. Most oral therapy trials reported to date have been small, underpowered, unblinded, relied on biased physician assigned endpoints, or in some cases, have been administratively stopped early without scientific justification or safety concerns.

Because COVID-19 is highly communicable, many U.S. ambulatory clinics do not care for patients with COVID-19 and studies suggest there has been little or no attempt to provide outpatient therapy to patients in the period before hospitalization (PriceHaywood et al., 2020). As the most notable early closure of a critically needed trial was U.S. National Institutes of Health study of hydroxychloroquine (HCQ) and azithromycin in ambulatory COVID-19 patients after 30 days with only 20 of 2000 budgeted patients enrolled (National Institutes of Health, 2020a,b). There has been no substantive federal effort since then on ambulatory trials and thus any future results are not expected in a time frame to influence public health policy (World Health Organisation, 2020). At the time of this writing, there are no planned trials of SMDT regimens designed to manage early viral replication, cytokine storm, and thrombosis in ambulatory patients with COVID19 (Fig. 3). Hence, there is an urgent need for innovative early SMDT in COVID-19 to achieve the goal of reducing the intensity and severity of symptoms and lessening the risk of hospitalization or death. This outpatient ambulatory push could have a dramatic impact on reducing the strain on healthcare systems.

In the absence of evidence from or a commitment to clinical trials of early therapy, other scientific information on the pathophysiology, treated natural history, and clinical judgement together must guide contemporary ambulatory management of COVID-19 (McCullough et al., 2020b). Observational studies reporting outcomes in patient populations managed consistently with empirically derived early intervention regimens currently provide an acceptable level of evidence for safety and efficacy of these widely available, inexpensive and safe alternatives to the current standard of non-intervention (Khan et al., 2020). Based on pathophysiology and observational data, each physician and patient using shared decision making set the course for COVID-19 management: watch- 
Table 1. Listing of early home-based treatment kits provided for acute COVID-19 illness by various countries.

\begin{tabular}{|c|c|c|}
\hline Country & Drugs and supplements & References \\
\hline Algeria & Chloroquine/Hydroxychloroquine & (Belayneh, 2020) \\
\hline Argentina & Ivermectin & (Mega, 2020) \\
\hline Brazil & $\begin{array}{l}\text { Hydroxychloroquine, Ivermectin, Azithromycin (Vitamin D and zinc only for those } \\
\text { who can afford) }\end{array}$ & $\begin{array}{l}\text { (Coronavirus a Tarde, 2020; Ministério da } \\
\text { Saúde, 2020) }\end{array}$ \\
\hline Bangladesh & Ivermectin, Doxycycline & (Trial Site News, 2020) \\
\hline Cameroon & Chloroquine/Hydroxychloroquine & (Belayneh, 2020; Bösmüller et al., 2020) \\
\hline China & $\begin{array}{l}\text { Chloroquine/Hydroxychloroquine plus other traditional medicine up to } 23 \text { different } \\
\text { Chinese herbal medicines }\end{array}$ & (Fan et al., 2020) \\
\hline Colombia & Ivermectin & (Mega, 2020) \\
\hline Egypt & Chloroquine/Hydroxychloroquine & (Mohhamad, 2020) \\
\hline France & Hydroxychloroquine, Azithromycin, and Lopinavir-Ritonavir & (Gérard et al., 2020) \\
\hline Ghana & Chloroquine/Hydroxychloroquine & (Isaac, 2020) \\
\hline India & Hydroxychlorquine, Ivermectin, alone or in combination with other drugs & (Vora et al., 2020) \\
\hline Korea & Hydroxychloroquine & (Hong et al., 2020) \\
\hline Mexico & Ivermectin, hydroxychloroquine & $($ Pacheco, 2020) \\
\hline Morocco & Chloroquine/Hydroxychloroquine & $\begin{array}{l}\text { (Brian, 2020; McFadyen et al., 2020; Mussa, } \\
\text { 2020) }\end{array}$ \\
\hline Mozanbique & Chloroquine/Hydroxychloroquine & (Belayneh, 2020; McFadyen et al., 2020) \\
\hline Nigeria & Chloroquine/Hydroxychloroquine & (Felix, 2020; McFadyen et al., 2020) \\
\hline Peru & Ivermectin, Azithromycin & $\begin{array}{l}\text { (Diario oficial del bicentenario, 2020; Trial } \\
\text { Site News, 2020) }\end{array}$ \\
\hline Senegal & Chloroquine/Hydroxychloroquine & (Huaxia, 2020; McFadyen et al., 2020) \\
\hline South Africa & Chloroquine/Hydroxychloroquine & (Katharine, 2020; McFadyen et al., 2020) \\
\hline Spain & $\begin{array}{l}\text { Patients who are already taking hydroxychloroquine within or outside of clinical tri- } \\
\text { als for COVID-19 as well as patients undergoing chronic treatment with these drugs } \\
\text { should continue taking them and, in any case, maintain their usual follow-ups with } \\
\text { their doctors }\end{array}$ & $\begin{array}{l}\text { (Agencia Española de Medicamentos y Pro- } \\
\text { ductos Sanitarios, 2020) }\end{array}$ \\
\hline Taiwan & Hydroxychloroquine & (Sheng, 2020) \\
\hline Uganda & Chloroquine/Hydroxychloroquine, Azithromycin & $\begin{array}{l}\text { (McFadyen et al., 2020; The Independent, } \\
\text { 2020) }\end{array}$ \\
\hline USA & $\begin{array}{l}\text { No kits provided from public health agencies, Association of American Physicians and } \\
\text { Surgeons Home COVID-19 Treatment Guide recommendends adjuvant neutraceuti- } \\
\text { cals, and sequenced multidrug therapy by prescription }\end{array}$ & (AAPS, 2020) \\
\hline
\end{tabular}

ful waiting in self-quarantine or empiric treatment with the aim of lessening the intensity and duration of symptoms and reducing the risk of hospitalization and death (Gopalakrishnan et al., 2020). Fortunately, most healthy individuals with COVID-19 under age 50 years have a self-limited illness and no specific treatment is advised in the absence of severe symptoms. However, they should be advised that development of lower respiratory symptoms warrant evaluation of oxygenation status and consideration chest imaging which may prompt interventions with documentation of hypoxemia or pulmonary infiltrates.

However, those over age 50 and or those with one or more comorbidity have increased risks for hospitalization and death over $1 \%$ which increase substantially up to $40 \%$ with advancing age and more medical illnesses (obesity, diabetes mellitus, heart disease, pulmonary disorders, renal disease, and malignancies) and thus, warrant early ambulatory treatment according to best medical judgement weighing the benefits and risks of oral therapy. SARS-CoV-2 as with many viral infections, may be amenable to multiple drugs early in its course but is less responsive to the same treatments when administration is delayed and given in the hospital (Vaduganathan et al., 2020). Innovative SMDT regimens for
COVID-19 utilize principles learned from hospitalized patients as well as data from treated ambulatory patients.

For the ambulatory patient with recognized signs and symptoms of COVID-19 on the first day (Fig. 2), often with nasal realtime reverse transcription or oral antigen testing not yet performed, the following three therapeutic principles apply (Centers for Disease Control and Prevention, 2020) : 1) combination anti-infective therapy to attenuate viral replication, 2) corticosteroids to modulate cytokine storm, and 4) antiplatelet agent/antithrombotic therapy to prevent and manage micro- or overt vascular thrombosis. For patients with cardinal features of the syndrome (fever, viral malaise, nasal congestion, loss of taste and smell, dry cough, etc) with pending or suspected false negative testing, therapy is the same as those with confirmed COVID-19.

\section{Reducing viral spread and contamination}

A major goal of self-quarantine is control of contagion (Nussbaumer-Streit et al., 2020). While there has been a great emphasis on masking and social distancing in congregate settings, many sources of information suggest the main place of viral transmission occurs in the home (respiratory, contact, oral-fecal) (Jef- 


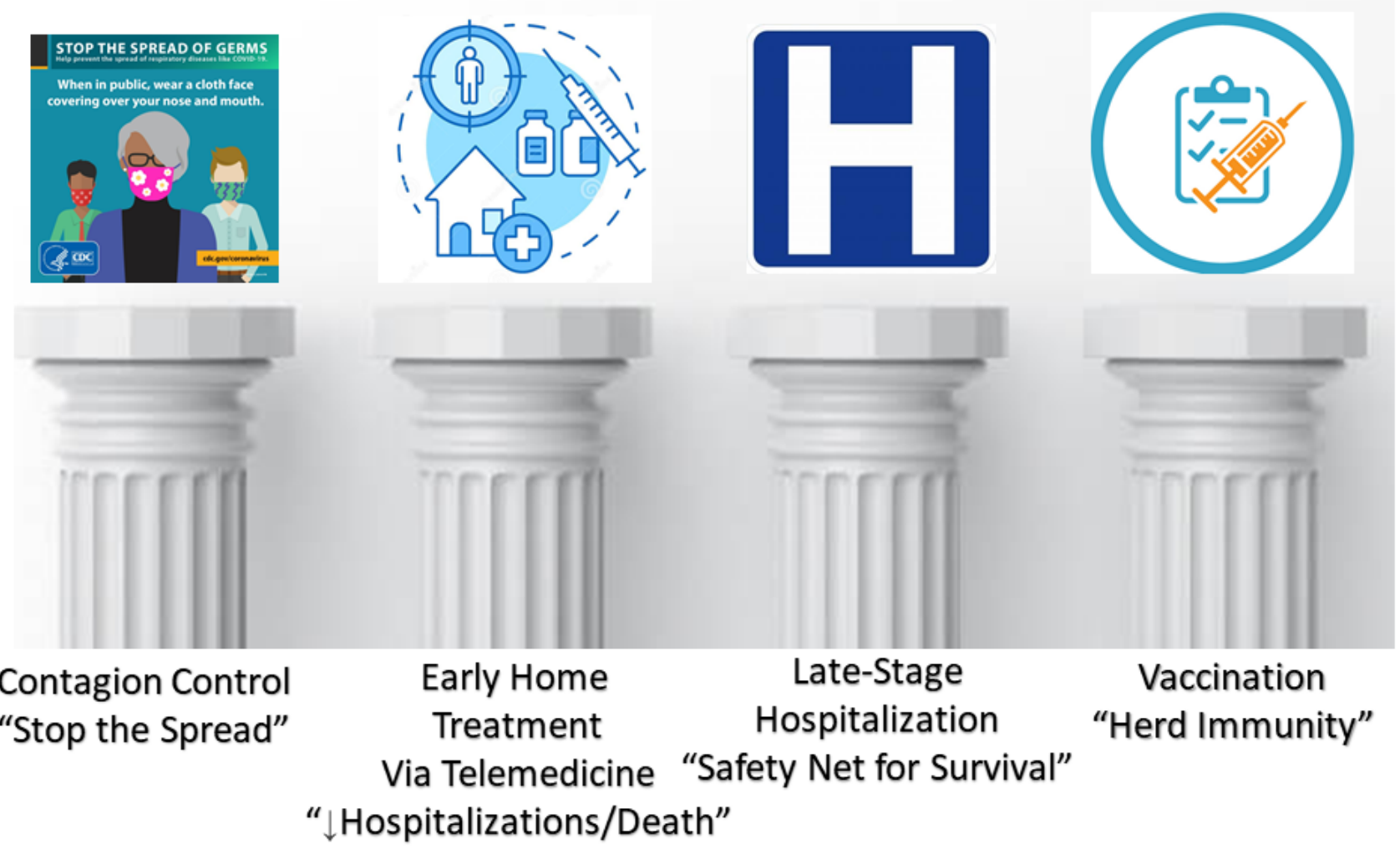

Fig. 1. The four pillars of pandemic response to COVID-19. The four pillars of pandemic response to COVID-19 are: 1) contagion control or efforts to reduce spread of SARS-CoV-2, 2) early ambulatory or home treatment of COVID-19 syndrome to reduce hospitalization and death, 3) hospitalization as a safety net to prevent death in cases that require respiratory support or other invasive therapies, 4) natural and vaccination mediated immunity that converge to provide herd immunity and ultimate cessation of the viral pandemic.

ferson et al., 2020; Xu et al., 2020). Masks for all unaffected contacts within the home as well as frequent use of hand sanitizer and hand washing is mandatory in the setting when one or more family members falls ill. Sterilizing surfaces such as countertops, door handles, phones, and other devices is advised. When possible, other close contacts can move out of the house and seek shelter free of SARS-CoV-2. Findings from multiple studies indicate that policies concerning control of the spread SARS-CoV-2 are only partially effective and extension into the home as the most frequent site of viral transfer is reasonable (Hsiang et al., 2020; Xiao et al., 2020). One of the great advantages of home treatment of COVID-19 is the ability of an individual or family unit to maintain isolation and complete contact tracing. If therapy is offered in the home with delivery of medications, then trips to urgent care centers, clinics, and hospitals can be reduced or eliminated. This limits spread to drivers, other patients, staff, and healthcare workers. On the contrary, therapeutic nihilism on the part of primary care physicians and health systems drives anxiety and panic among patients with acute COVID-19 who feel abandoned, making them more likely to break quarantine and seek aid at urgent care centers, emergency rooms and hospitals.

SARS-CoV-2 exists outside the human body in a bioaerosol of airborne particles and droplets. Since exhaled air in an infected person is considered to be "loaded" with particulate inoculum, each exhalation and inhalation in theory reinoculates the nasophar- ynx and tracheobronchial tree (Chen, 2020). We propose that fresh circulating air could reduce reinoculation and potentially lessen the severity of illness and possibly limit household spread during quarantine (Melikov et al., 2020). This calls for open windows, fans for aeration, or spending long periods of time outdoors away from others with no face covering in order to disperse and not reinhale the viral bioaerosol. These are principles used in the hospital with negative pressure ventilation deployed in isolation rooms to reduce bioaerosol contagion.

\section{Adjunctive nutraceuticals}

There has been considerable interest and study of the use of micronutrients and supplements for COVID-19 prophylaxis and treatment in combination with anti-infectives as first proposed by Zelenko and colleagues (Derwand et al., 2020). In general these agents are not curative but assist in treatment regimens to augment the therapeutic response. The aim of supplementation is to replenish in those with deficiencies associated with COVID-19 mortality, and to aid in reducing viral replication and tissue damage. Zinc deficiency is common among adults (Sharma et al., 2020). Zinc alone is a potent inhibitor of viral replication. Zinc in combination with hydroxychloroquine (HCQ) is potentially synergistic in reducing viral replication since HCQ is a zinc ionophore facilitating intracellular entry and inhibition of intracellular viral replication (Derwand and Scholz, 2020). This readily available nontoxic therapy could be deployed at the first signs of COVID-19 (Rahman 


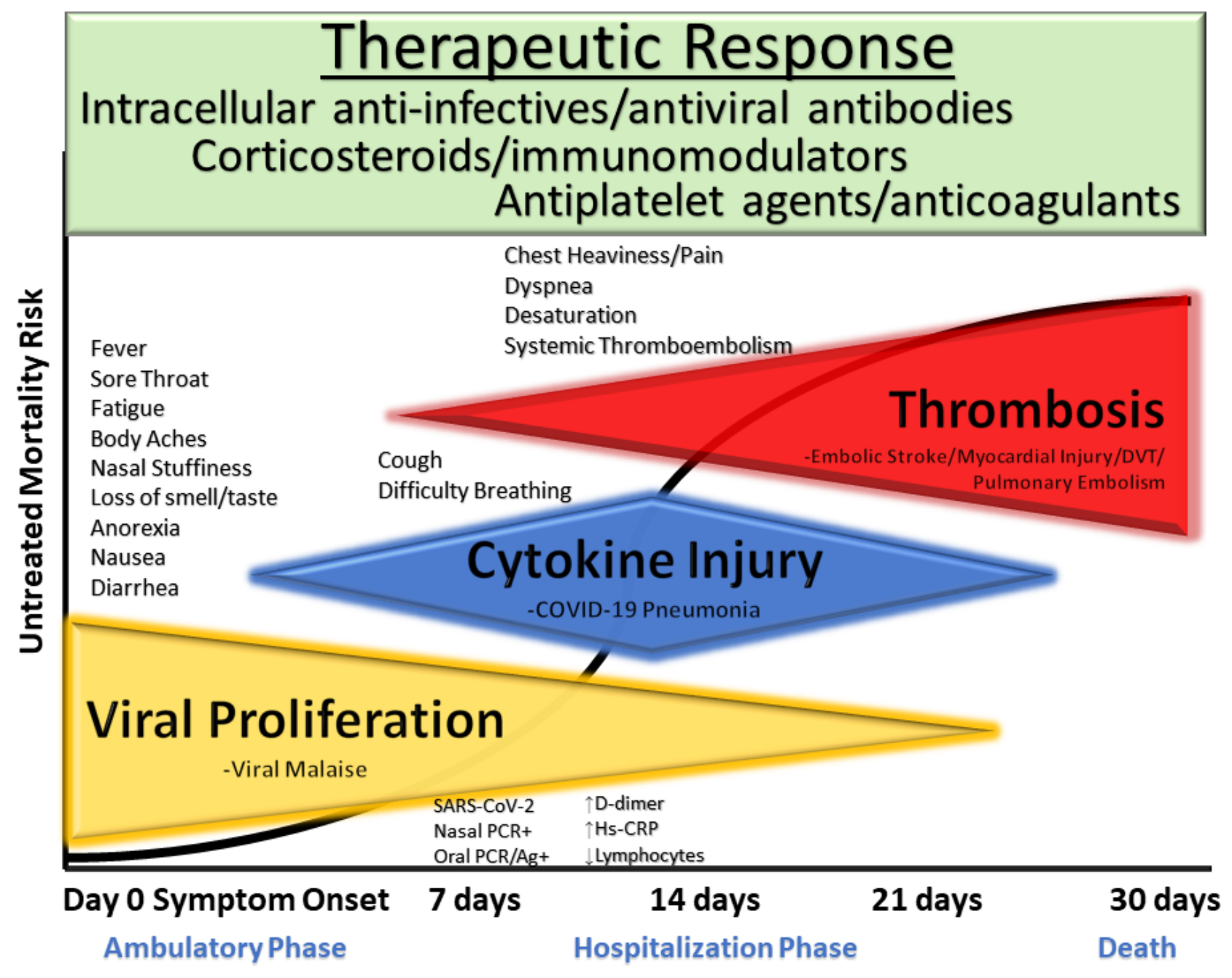

Fig. 2. Major dimensions of COVID-19 infection that call for a multi-drug strategy in the early ambulatory period with available medications including antiinfectives (hydroxychloroquine, ivermectin, azithromycin, doxycycline), corticosteroids, and anti-platelet drugs and anticoagulants. The three dimensions of the infection and their time-course allow for the sequenced multi-drug approach to be utilized with the goal of reducing hospitalization and death.

and Idid, 2020). Zinc sulfate $220 \mathrm{mg}$ (50 mg elemental zinc) can be taken orally per day (Pormohammad et al., 2020).

Vitamin D deficiency has been associated with increased COVID-19 mortality and is commonly confounded by increasing age, obesity, diabetes, darker skin tones, and lack of fitness (Meltzer et al., 2020; Pereira et al., 2020) With good rationale, one small, randomized trial of vitamin $\mathrm{D}_{3}$ supplementation found reduced mortality in patients with COVID-19 (Entrenas et al., 2020; Zhang et al., 2020a). The suggested dose is $5000 \mathrm{IU}$ of vitamin $\mathrm{D}_{3}$ per day.

Vitamin $\mathrm{C}$ has been used in a variety of viral infections and could be useful in combination with other supplements in COVID19 (Carr and Rowe, 2020). Multiple randomized trials of vitamin C given intravenously or orally are planned or in progress at the time of this writing (Beigmohammadi et al., 2020; Liu et al., 2020) A reasonable dose would be vitamin C $3000 \mathrm{mg}$ po qd.

Quercetin is a polyphenol that has a theoretical mechanism of action that could reduce the activity of a SARS-CoV-2 entry through the ACE2 receptor, inhibit viral proteases via conveyance of zinc, and attenuate inflammatory responses mediated through interleukin-6 (Bastaminejad and Bakhtiyari, 2020; Cione et al., 2019; Dabbagh-Bazarbachi et al., 2014; Derosa et al., 2020). The mechanisms of action favorably affect viral replication and immune response, so it is conceivable that this agent taken in combination with others discussed could play an assistive role in reducing early viral amplification and tissue damage (Colunga Biancatelli et al., 2020). The suggested dose of quercetin is $500 \mathrm{mg}$ po bid.

\section{Anti-infective therapy with intracellular activity}

Quickly reducing the rate, quantity, and duration of viral replication, is a goal of antiviral therapy aimed at starting on the first day of symptomatic illness. The compelling rationale for prompt therapy is to minimize the degree of direct viral injury to the respiratory epithelium, vascular endothelium, and organs (Izzedine et al., 2020). Maladaptive host responses dependant on replication of SARS-CoV-2 could be attenuated by early initiation of combination anti-infectives including activation of inflammatory cells, cytokines, endothelial injury, and thrombosis (Singhania et al., 2020). Because SARS-CoV-2 infection is associated with severe disease and increased mortality in patients over age 50 years and those with one or more comorbidities, clinicians should use of at least two commercially available, anti-infective agents where it is 


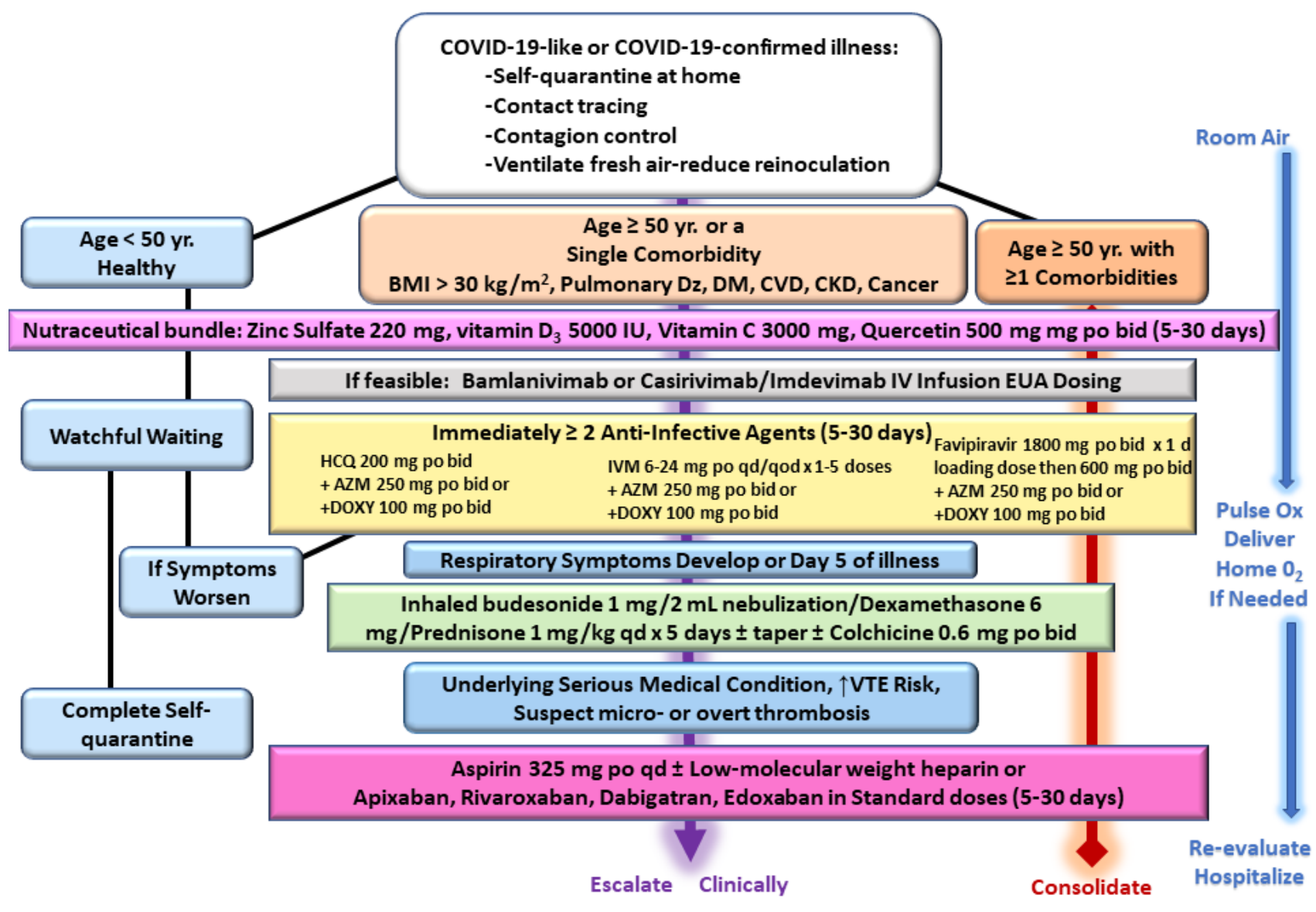

$\mathrm{BMI}=$ body mass index, $\mathrm{Dz}=$ disease, $\mathrm{DM}=$ diabetes mellitus, $\mathrm{CVD}=$ cardiovascular disease, $\mathrm{CKD}=$ chronic kidney disease, $\mathrm{yr}=\mathrm{years}, \mathrm{HCQ}=$ hydroxychloroquine, $\mathrm{AZM}=\mathrm{azithromycin}$, DOXY=doxycycline, IVM=Ivermectin, VTE=venous thrombo-embolic, EUA=Emergency Use Authorization (U.S. administration)

Fig. 3. Sequential multidrug treatment algorithm for ambulatory acute COVID-19 like and confirmed COVID-19 illness in patients in selfquarantine. $\mathrm{Yr}=$ year, $\mathrm{BMI}=$ body mass index, $\mathrm{Dz}=$ disease, $\mathrm{DM}=$ diabetes mellitus, $\mathrm{CVD}=$ cardiovascular disease, chronic kidney disease, $\mathrm{HCQ}=$ hydroxychloroquine, $\mathrm{IVM}=$ ivermectin, $\mathrm{Mgt}=$ management, $\mathrm{Ox}=$ oximetry, reproduced with permission from reference.

appropriately considered clinically indicated, medically necessary "off-label" prescription (Shojaei and Salari, 2020). Conversely, the decision to withhold oral therapy early in a potentially fatal illness should be made in a shared-decision making process with the patient given the full understanding that the natural untreated history of COVID-19 in high risk adults includes the risk of hospitalization, hospital-acquired complications, and death. The physician and patient should understand that the only method by which a hospitalization could be avoided would be the empiric use of SMDT that have a reasonable chance of success with acceptable safety. Recent expanded use authorization of IV administration of bamlanivimab is another option available to a limited number of patients, but supplies will be insufficient to treat everyone who meets the broad criteria for the therapy, so availability of oral alternatives remains essential.

\section{Hydroxychloroquine}

Hydroxychloroquine (HCQ) is an antimalarial/antiinflammatory drug that impairs endosomal transfer of virions within human cells. HCQ is also a zinc ionophore that conveys zinc intracellularly to block the SARS-CoV-2 RNA-dependent RNA polymerase which is the core enzyme of the virus replication (te Velthuis et al., 2010). A continuously updated synthesis of HCQ studies supports the following (COVID-19 Treatment,
2020): 1) $63 \%$ of studies of HCQ administered late in the hospital course have demonstrated benefit, 2) $100 \%$ of the early treatment studies have demonstrated benefit with a composite $64 \%$ relative risk reduction in the progression of disease, hospitalization, and death (Arshad et al., 2020; Mikami et al., 2020; Prodromos and Rumschlag, 2020; Rosenberg et al., 2020). The small randomized trials to date are inconclusive for the following reasons: 1) no placebo control, 2) unblinded, 3) altered primary endpoints, 4) biased unblinded physician assigned endpoints (such as need for oxygen), 5) markedly truncated sample sizes and administrative termination of trials, 6) pretreatment with other antivirals.

Hydroxychloroquine was approved by the U.S. Food and Drug Administration in 1955, has been used by hundreds of millions of people worldwide since then, is sold over the counter in many countries and has a well characterized safety profile (Fram et al., 2020; Schrezenmeier and Dörner, 2020). Asymptomatic QT prolongation is well-recognized though an infrequent $(<1 \%)$ occurrence with HCQ (Prodromos et al., 2020). In those with glucose6-phosphate dehydrogenase deficiency HCQ should not be used (Aguilar, 2020). In the setting of acute severe COVID-19 illness, symptomatic arrhythmias can develop in the absence of HCQ and are attributed to cytokine storm and critical illness (Elsaid et al., 2020). Data safety and monitoring boards have not declared safety concerns in HCQ clinical trial published to date. Rare pa- 
tients with a personal or family history of prolonged QT syndrome, those on additional QT prolonging, contraindicated drugs (e.g. dofetilide, sotalol), should be treated with caution and a plan to monitor the QTc in the ambulatory setting. A typical HCQ regimen is $200 \mathrm{mg}$ bid for 5 to 30 days depending on continued symptoms.

\section{Ivermectin}

Ivermectin (IVM) is a broad spectrum anti-parasitic agent that has been shown to have anti-viral activity against a range of viruses including recently, SARS-CoV-2 (Heidary and Gharebaghi, 2020). This drug is well tolerated, has a high therapeutic index and proven safety profile with over 3.7 billion treatments, and has been used alone or combined with either doxycycline or azithromycin in early clinical studies of patients with COVID-19 (Rahman et al., 2020). There are a number of randomized and prospective studies and all have shown efficacy in clinical outcomes at the time of this report (Alam et al., 2020; Chowdhury et al., 2020; Gorial et al., 2020; Khan et al., 2020; Nunez et al., 2020). Hence, it is reasonable in patients where HCQ cannot be used and favipiravir is not available, that IVM $(200-600 \mathrm{mcg} / \mathrm{kg}$ [6-36 mg] single oral dose given daily or every other day for 23 administrations) could be the base of SMDT intended to reduce viral replication early in the course of COVID-19. However, uncertainty remains at this time concerning optimal dosing and schedule (Schmith et al., 2020). In the ICON study, IVM use in the hospital was associated with a $48 \%$ relative risk reduction in COVID-19 mortality (Rajter et al., 2020). Currently, there are 36 randomized clinical trials of ivermectin alone or in combination for ambulatory and hospitalized patients listed on clinicaltrials.gov.

\section{Favipiravir}

Favipiravir is an oral selective inhibitor of RNA-dependent RNA polymerase, and is approved for ambulatory use in COVID19 in multiple countries (Coomes and Haghbayan, 2020). Favipiravir is safe and it shortens viral nasal shedding to less than 7 days in most studies (Ivashchenko et al., 2020; Pilkington et al., 2020). A dose administration could be $1600-1800 \mathrm{mg}$ po bid on day 1 , following by $600-800 \mathrm{mg}$ po bid for 14 days depending on the dose sizes available in 30 different countries (Li et al., 2020). At the time of this writing, there are large ambulatory clinical trials in progress but are not expected to report in time to aid in the crisis at hand in the U.S.

\section{Antibiotics with intracellular anti-infective activity}

Azithromycin (AZM) is a commonly used macrolide antibiotic that has antiviral properties mainly attributed to reduced endosomal transfer of virions as well as established anti-inflammatory effects (Pani et al., 2020). French reports indicated that AZM in combination with HCQ was associated with reduced durations of viral shedding, fewer hospitalizations, and reduced mortality as compared to those untreated (Lagier et al., 2020; Million et al., 2020). In a large observational inpatient study $(n=2451)$, those who received AZM alone had an adjusted hazard ratio for mortality of $1.05,95 \%$ CI $0.68-1.62, P=0.83$ (Colunga Biancatelli et al., 2020). The combination of HCQ and AZM has been considered a standard of care outside the US for COVID-19 in more than 300,000 older adults with multiple comorbidities (Risch, 2020).
AZM like HCQ can prolong the QTc in $<1 \%$ of patients, yet has demonstrated safety in co-administration with HCQ (Huang et al., 2020). A reasonable regimen is $250 \mathrm{mg}$ po bid for 5 to 30 days for persistent symptoms or evidence of bacterial superinfection.

Doxycycline is another common antibiotic with multiple intracellular effects that may reduce viral replication, cellular damage, and expression of inflammatory factors (Malek et al., 2020; Sodhi and Etminan, 2020). It has been shown to have in vitro activity against COVID-19 at clinically used concentrations, acting in post-entry stages of the infection with SARS-CoV-2 in Vero $\mathrm{E}_{6}$ cells (Gendrot et al., 2020). It has also been shown to concentrate in the lungs at levels twice that of plasma. When combined with ivermectin early in the infection it appears to enhance efficacy to near complete eradication of COVID-19 in less than 10 days. This drug has no effect on cardiac conduction and has the main caveat of gastrointestinal upset and esophagitis. Both AZM and doxycycline has the advantage of offering antibacterial coverage for superimposed bacterial and atypical infection in the upper respiratory tract (Ailani et al., 1999). Doxycycline can be dosed $200 \mathrm{mg}$ po followed by $100 \mathrm{mg}$ po bid for 5 to 30 days for persistent symptoms or evidence of bacterial superinfection.

\section{Antibody therapy}

Recently, bamlanivimab a monoclonal antibody directed against the SARS-CoV-2 spike protein has been approved for the early ambulatory treatment of COVID-19. In the BLAZE-1 randomized trial, the pooled secondary endpoint of COVID-19 hospitalizations occurred 4/136 and 7/69 of the Bamlanivimab and placebo groups respectively (Chen, 2020). While these results are not considered conclusive nor robust, given the emergency context, bamlanivimab is authorized for COVID-19 patients who are 12 years of age and older weighing at least $40 \mathrm{~kg}$, and who are at high risk for progressing to severe COVID-19 or hospitalization. The authorized dosage for bamlanivimab is a single IV infusion of $700 \mathrm{mg}$ administered as soon as possible after positive viral test for SARS-CoV-2 and within 10 days of symptom onset. The infusion should occur over an hour with another hour of monitoring for systemic reactions (expected $<5 \%$ ).

A humanized antibody blend of casirivimab and imdevimab has also received emergency approval in the United States and for a similar population as bamlanivimab. This pair of antibodies binds at different regions of the SARS-CoV-2 spike protein. This antibody combination is dosed $1,200 \mathrm{mg}$ of casirivimab and 1,200 $\mathrm{mg}$ of imdevimab together as a single IV infusion over at least 60 minutes with another hour of monitoring for reactions (Regeneron Pharmaceuticals, Inc., 2020). In the phase II program, the secondary endpoint of hospitalization occurred in 8/434 and 10/231 of casirivimab/imdevimab and placebo groups, respectively. These results should be interpreted with caution and cannot be characterized as being conclusive or robust, yet as with all therapies discussed in this paper, casirivimab/imdevimab can be integrated into an innovative sequenced multi-drug regimen for SARS-CoV-2 infection.

If SARS-CoV-2 is diagnosed by rapid testing in a facility that performs antibody infusion such as an emergency room, urgent care center, or clinic, it is reasonable to start COVID-19 with the antibody infusion. Conversely, if it can be safely arranged by home infusion while maintaining quarantine, physicians may prescribe this therapy to augment the effects of longer courses of oral treat- 
ment. At this time, it is unattractive to ask a patient to break quarantine and risk spread of infection to drivers and healthcare personnel in order to receive an outpatient infusion.

\section{Corticosteroids}

The manifestations of COVID-19 that prompt hospitalization and that may well lead to multi-organ system failure are attributed to a cytokine storm. The characteristic profile of an acutely ill COVID-19 patient includes leukocytosis with a relative neutropenia. Among COVID-19 patients, serum IL-6 and IL-10 levels are elevated in the critically ill (Han et al., 2020). In COVID-19, some of the first respiratory findings are cough and difficulty breathing. These features are attributable to inflammation and cytokine activation. Early use of oral corticosteroids is a rational intervention for COVID-19 patients with these features as they would be in other inflammatory lung disorders (Kolilekas et al., 2020; Singh et al., 2020). Inhaled budesonide $1 \mathrm{mg} / 2 \mathrm{~mL}$ via nebulizer or 200 $\mathrm{mcg} /$ inhaler up to every four hours can be utilized however, there are no published reports of efficacy in COVID-19. The RECOVERY trial randomized 6425 hospitalized patients with COVID-19 in a $2: 1$ ratio to open label dexamethasone $6 \mathrm{mg}$ po/IV qd for up to 10 days and found dexamethasone reduced mortality, HR = $0.65,95 \%$ CI $0.51-0.82, P<0.001$ (Horby et al., 2020) . Concordantly, a meta-analysis involving 1703 critically ill COVID-19 patients found a $36 \%$ relative risk reduction in death (Sterne et al., 2020). Safety concerns regarding prolonged viral replication with steroids have not been substantiated (Masiá et al., 2020). A clinical extension of these findings is administration of steroids in COVID-19 patients at home on day five or beyond with moderate or greater pulmonary symptoms (Szente Fonseca et al., 2020). Dexamethasone $6 \mathrm{mg}$ po qd or prednisone $1 \mathrm{mg} / \mathrm{kg}$ can be given orally per day for five days with or without a subsequent taper.

\section{Colchicine}

Colchicine is a non-steroidal anti-mitotic drug used in gout and pericarditis which blocks metaphase of inflammatory cells by binding to the ends of microtubules preventing their intracellular assembly. The GRECCO-19 randomized open-label trial in 105 hospitalized patients with COVID-19 (treated with HCQ and AZM in 98 and $93 \%$ respectively) found that colchicine was associated with a reduction in D-dimer levels and improved clinical outcomes (Deftereos et al., 2020). The clinical primary end point (2-point change in World Health Organization ordinal scale) occurred in $14.0 \%$ in the control group (7 of 50 patients) and $1.8 \%$ in the colchicine group ( 1 of 55 patients) (odds ratio, $0.11 ; 95 \% \mathrm{CI}$, 0.01-0.96; $P=0.02$ ) (World Health Organisation, 2020). Because the short-term safety profile is well understood, it is reasonable to consider this agent along with corticosteroids in an attempt to reduce the effects of cytokine storm and myopericarditis. A dosing scheme of $0.6 \mathrm{mg}$ po bid $\mathrm{x} 3$ days then $0.6 \mathrm{mg}$ po qd for 30 days can be considered.

\section{Antiplatelet agents and antithrombotics}

Multiple studies have described increased rates of pathological macro and micro-thrombosis (Bösmüller et al., 2020; McFadyen et al., 2020). COVID-19 patients have described chest heaviness associated with desaturation that suggests the possibility of pulmonary thrombosis (Bhandari et al., 2020). Multiple reports have described elevated D-dimer levels in acutely ill COVID-19 patients which has been consistently associated with increased risk of deep venous thrombosis and pulmonary embolism (Artifoni et al., 2020; Chan et al., 2020; Mestre-Gómez et al., 2020). Autopsy studies have described pulmonary micro thrombosis and overt embolism with deep venous thrombus found in over half of fatal COVID-19 cases (Ackermann et al., 2020; Burlacu et al., 2020). These observations support the hypothesis that a unique endothelial injury and thrombosis are playing a role in oxygen desaturation, a cardinal reason for hospitalization and supportive care (Zhang et al., 2020b). Because thromboxane $A_{2}$ is markedly upregulated with SARS-CoV-2 infection, early administration of aspirin $325 \mathrm{mg}$ per day is advised for initial antiplatelet and anti-inflammatory effects (Chow et al., 2020; Glatthaar-Saalmüller et al., 2017; A. Gupta et al., 2020a; Turshudzhyan, 2020). Ambulatory patients can also be treated with subcutaneous low-molecular weight heparin or with oral novel anticoagulant drugs (apixaban, rivaroxaban, edoxaban, dabigatran) in dosing schemes similar to those used in outpatient thromboprophylaxis. In a retrospective study of 2773 COVID-19 inpatients, $28 \%$ received anticoagulant therapy within 2 days of admission, and despite being used in more severe cases, anticoagulant administration was associated with a reduction in mortality, $\mathrm{HR}=0.86$ per day of therapy, $95 \% \mathrm{CI}: 0.82-0.89 ; P<0.001$. Contemporary use of in hospital anticoagulants has remained in $\sim 30 \%$ of cases (Vahidy et al., 2020) . Pre-emptive use of low molecular weight heparin or novel anticoagulants have been associated with $>50 \%$ reduction in COVID-19 mortality (Billett et al., 2020). Anticoagulants also reduce death in COVID-19 hospitalized patients with thrombotic complications, elevated D-dimer levels, and higher comorbidity scores (Tang et al., 2020) . Finally, many acutely ill outpatients also have general indications or risk for cardioembolic/venous thromboembolic prophylaxis applicable to COVID-19 (Moores et al., 2020; Ruocco et al., 2020). There are ambulatory randomized trials of aspirin and novel oral anticoagulants underway. However, given reports of catastrophic stroke and systemic thromboembolism and the large reductions in mortality for both prophylactic and therapeutic use, administration of aspirin $325 \mathrm{mg}$ po qd for all COVID-19 high-risk patients and systemic anticoagulation is prudent in patients with a history of heart, lung, kidney, or malignant disease (Yamakawa et al., 2020).

\section{Delivery of oxygen and monitoring}

Telemedicine is a tractable means for the initial evaluation and management of COVID-19 allowing the patient to remain in selfquarantine at home. Clinical impressions of the patient can be gained with audio and video feeds. Key supplemental information includes self/family measurement of vital signs and temperature. A significant component of safe outpatient management is maintenance of arterial oxygen saturation on room air or prescribed home oxygen (oxygen concentrators) under direct supervision by daily telemedicine with escalation to hospitalization for assisted ventilation if needed. Self-proning could be entertained for medically sophisticated patients with good at-home monitoring (Westafer et al., 2020) .

The interventions discussed in this review could be extended to seniors in COVID-19 treatment units within nursing homes and other non-hospital settings. In addition to oral medications, these centers could deliver intravenous fluid and parenteral medications (i.e. bamlanivimab, casirivimab/imdevimab), oxygen, and assisted pressure ventilation with the goal of reducing the risk of 
hospital transfer.

\section{Summary}

The SARS-CoV-2 outbreak is a once in a hundred-year pandemic that has not been addressed by rapid establishment of infrastructure amenable to support the conduct of large, randomized trials in outpatients in the community setting. The early flu-like stage of viral replication provides a therapeutic window of tremendous opportunity to potentially reduce the risk of more severe sequelae in high risk patients. Precious time is squandered with a "wait and see" approach in which there is no anti-viral treatment as the condition worsens, possibly resulting in unnecessary hospitalization, morbidity, and death. Once infected, the only means of preventing a hospitalization in a high-risk patient is to apply treatment before arrival of symptoms that prompt paramedic calls or emergency room visits. Given the current failure of government support for randomized clinical trials evaluating widely available, generic, inexpensive therapeutics, and the lack of instructive outpatient treatment guidelines (U.S., Canada, U.K., Western EU, Australia, some South American Countries), clinicians must act according to clinical judgement and in shared decision making with fully informed patients. Early SMDT developed empirically based upon pathophysiology and evidence from randomized data and the treated natural history of COVID-19 has demonstrated safety and efficacy. In newly diagnosed, high-risk, symptomatic patients with COVID-19, SMDT has a reasonable chance of therapeutic gain with an acceptable benefit-to-risk profile. Until the pandemic closes with population-level herd immunity potentially augmented with vaccination, early ambulatory SMDT should be a standard practice in high risk and severely symptomatic acute COVID-19 patients beginning at the onset of illness.

Footnote: To understand which drugs are being used in the early treatment of COVID-19 in these countries' websites of government agencies such as Brazil, Peru, Spain, Taiwan, and USA were searched. We also looked for researchers published in PUBMED by China, France, India, Korea, and African countries. Additional Information was also obtained from reliable sources of internet such as Argentina, Bangladesh, Colombia, Mexico and African Countries.

\section{Author contributions}

PAM wrote the first draft and created the figures, all authors provided critical edits and comments, PEA did the final proofreading and key finalization of the text. SR created the first draft of the table.

\section{Acknowledgements}

We are indebted to Jeremy Snavely who assisted in manuscript preparation.

\section{Funding}

None related.

\section{Conflict of Interest}

There is nothing to disclose. Author had access to the data and wrote the manuscript.

Submitted: November 28, 2020

Revised: December 08, 2020

Accepted: December 15, 2020

Published: December 30, 2020

\section{References}

AAPS. (2020) A Guide to Home-Based COVID Treatment. American Association of Pharmaceutical Scientists. Available at: https://aapson line.org/covidpatientguide/.

Ackermann, M., Verleden, S. E., Kuehnel, M., Haverich, A., Welte, T., Laenger, F., Vanstapel, A., Werlein, C., Stark, H., Tzankov, A., Li, W. W., Li, V. W., Mentzer, S. J. and Jonigk, D. (2020) Pulmonary Vascular Endothelialitis, Thrombosis, and Angiogenesis in Covid-19. New England Journal of Medicine 383, 120-128.

Agencia Española de Medicamentos y Productos Sanitarios. Información acerca del uso de hidroxicloroquina para el tratamiento de COVID-19. Available at https://www.aemps.gob.es/informa/notasinfo rmativas/laaemps/2020-laaemps/informacion-acerca-del-u so-de-hidroxicloroquina-para-el-tratamiento-de-covid-19/ (Acessed: 11 November, 2020).

Aguilar, J. (2020) Hemolytic Anemia in a Glucose-6-Phosphate Dehydrogenase-Deficient Patient Receiving Hydroxychloroquine for COVID-19: A Case Report. The Permanente Journal 24, 20.158.

Ailani, R. K., Agastya, G., Ailani, R. K., Mukunda, B. N. and Shekar, R. (1999) Doxycycline is a cost-effective therapy for hospitalized patients with community-acquired pneumonia. Archives of internal medicine 159, 266-270.

Alam, M. T., Murshed, R., Bhiuyan, E., Saber, S., Alam, R. F. \& Choudhury Robin, R. (2020). A Case Series of 100 COVID-19 Positive Patients Treated with Combination of Ivermectin and Doxycycline. Journal of Bangladesh College of Physicians and Surgeons, 38.

Argenziano, M. G., Bruce, S. L., Slater, C. L., Tiao, J. R., Baldwin, M. R., Barr, R. G., Chang, B. P., Chau, K. H., Choi, J. J., Gavin, N., Goyal, P., Mills, A. M., Patel, A. A., Romney, M. S., Safford, M. M., Schluger, N. W., Sengupta, S., Sobieszczyk, M. E., Zucker, J. E., Asadourian, P. A., Bell, F. M., Boyd, R., Cohen, M. F., Colquhoun, M. I., Colville, L. A., de Jonge, J. H., Dershowitz, L. B., Dey, S. A., Eiseman, K. A., Girvin, Z. P., Goni, D. T., Harb, A. A., Herzik, N., Householder, S., Karaaslan, L. E., Lee, H., Lieberman, E., Ling, A., Lu, R., Shou, A. Y., Sisti, A. C., Snow, Z. E., Sperring, C. P., Xiong, Y., Zhou, H. W., Natarajan, K., Hripcsak, G. and Chen, R. (2020) Characterization and clinical course of 1000 patients with coronavirus disease 2019 in New York: retrospective case series. British Medical Journal 369, m1996.

Arshad, S., Kilgore, P., Chaudhry, Z. S., Jacobsen, G., Wang, D. D., Huitsing, K., Brar, I., Alangaden, G. J., Ramesh, M. S., McKinnon, J. E., O'Neill, W. and Zervos, M. (2020) Treatment with hydroxychloroquine, azithromycin, and combination in patients hospitalized with COVID-19. International Journal of Infectious Diseases 97, 396403 .

Artifoni, M., Danic, G., Gautier, G., Gicquel, P., Boutoille, D., Raffi, F., Néel, A. and Lecomte, R. (2020) Systematic assessment of venous thromboembolism in COVID-19 patients receiving thromboprophylaxis: incidence and role of D-dimer as predictive factors. Journal of Thrombosis and Thrombolysis 50, 211-216.

Bastaminejad, S. and Bakhtiyari, S. (2020) Quercetin and its relative therapeutic potential against COVID-19: A retrospective review and prospective overview. Current Molecular Medicine 20. Epub ahead of print.

Beigmohammadi, M. T., Bitarafan, S., Hoseindokht, A., Abdollahi, A., Amoozadeh, L., Mahmoodi Ali Abadi, M. and Foroumandi, M. (2020) Impact of vitamins A, B, C, D, and E supplementation on improvement and mortality rate in ICU patients with coronavirus-19: a structured summary of a study protocol for a randomized controlled trial. Trials 21, 614 .

Belayneh, A. (2020) Off-Label Use of Chloroquine and Hydroxychloroquine for COVID-19 Treatment in Africa Against WHO Recommendation. Research and Reports in Tropical Medicine 11, 61-72.

Bhandari, S., Rankawat, G., Bagarhatta, M., Singh, A., Singh, A., Gupta, V., Sharma, S. and Sharma, R. (2020) Clinico-Radiological Evaluation and Correlation of CT Chest Images with Progress of Disease in COVID-19 Patients. The Journal of the Association of Physicians of India 68, 34-42. 
Bhimraj, A., Morgan, R. L., Shumaker, A. H., Lavergne, V., Baden, L., Cheng, V. C. C., Edwards, K. M., Gandhi, R., Gallagher, J., Muller, W. J., O’Horo, J. C., Shoham, S., M. Murad, H., Mustafa, R. A., Sultan, S. and Falck-Ytter, Y. (2020) Infectious diseases society of America guidelines on the treatment and management of patients with COVID19. Available at: https://www.idsociety.org/practice-guideline /covid-19-guideline-treatment-and-management/.

Billett, H. H., Reyes-Gil, M., Szymanski, J., Ikemura, K., Stahl, L. R., Lo, Y., Rahman, S., Gonzalez-Lugo, J. D., Kushnir, M., Barouqa, M., Golestaneh, L. and Bellin, E. (2020) Anticoagulation in COVID-19: Effect of Enoxaparin, Heparin, and Apixaban on Mortality. Thromb Haemost. Epub ahead of print.

Brian, W. (2020) Covid-19: Algeria and Morocco continue using chloroquine despite concerns. al-bab.com. Available at: https://al-bab.com/blog/2020/05/covid-19-algeria-and -morocco-continue-using-chloroquine-despite-concerns (Accessed: 11 November, 2020).

Bösmüller, H., Traxler, S., Bitzer, M., Häberle, H., Raiser, W., Nann, D., Frauenfeld, L., Vogelsberg, A., Klingel, K. and Fend, F. (2020) The evolution of pulmonary pathology in fatal COVID-19 disease: an autopsy study with clinical correlation. Virchows Archiv 477, 349-357.

Burlacu, A., Genovesi, S., Popa, I. V. and Crisan-Dabija, R. (2020) Unpuzzling COVID-19 Prothrombotic State: Are Preexisting Thrombophilic Risk Profiles Responsible for Heterogenous Thrombotic Events? Clinical and Applied Thrombosis/Hemostasis 26, 1076029620952884.

Carr, A. C. and Rowe, S. (2020) The Emerging Role of Vitamin C in the Prevention and Treatment of COVID-19. Nutrients 12.

Chan, K. H., Slim, J. and Shaaban, H. S. (2020) Pulmonary Embolism and Increased Levels of D-Dimer in Patients with Coronavirus Disease. Emerging Infectious Diseases 26, 2522-2533.

Chen, L. D. (2020) Effects of ambient temperature and humidity on droplet lifetime - A perspective of exhalation sneeze droplets with COVID-19 virus transmission. International Journal of Hygiene and Environmental Health 229, 113568.

Chen, P., Nirula, A., Heller, B., Gottlieb, R. L., Boscia, J., Morris, J., Huhn, G., Cardona, J., Mocherla, B., Stosor, V., Shawa, I., Adams, A. C., Van Naarden, J., Custer, K. L., Shen, L., Durante, M., Oakley, G., Schade, A. E., Sabo, J., Patel, D. R., Klekotka, P. and Skovronsky, D. M. (2020) SARS-CoV-2 Neutralizing Antibody LY-CoV555 in Outpatients with Covid-19. The New England Journal of Medicine NEJMoa2029849. Epub ahead of print.

Chow, J. H., Khanna, A. K., Kethireddy, S., Yamane, D., Levine, A., Jackson, A. M., McCurdy, M. T., Tabatabai, A., Kumar, G., Park, P., Benjenk, I., Menaker, J., Ahmed, N., Glidewell, E., Presutto, E., Cain, S., Haridasa, N., Field, W., Fowler, J. G., Trinh, D., Johnson, K. N., Kaur, A., Lee, A., Sebastian, K., Ulrich, A., Peña, S., Carpenter, R., Sudhakar, S., Uppal, P., Fedeles, B. T., Sachs, A., Dahbour, L., Teeter, W., Tanaka, K., Galvagno, S. M., Herr, D. L., Scalea, T. M. and Mazzeffi, M. A. (2020) Aspirin Use is Associated with Decreased Mechanical Ventilation, ICU Admission, and In-Hospital Mortality in Hospitalized Patients with COVID-19. Anesthesia \& Analgesia. Online ahead of print.

Chowdhury, A., Shahbaz, M., Karim, M.R., Islam, J., Guo, D. and He, S. (2020). A Randomized Trial of Ivermectin-Doxycycline and Hydroxychloroquine-Azithromycin therapy on COVID19 patients. Research Square, published online. doi: 10.21203/rs.3.rs-38896/v1

Cione, E., La Torre, C., Cannataro, R., Caroleo, M. C., Plastina, P. and Gallelli, L. (2019) Quercetin, Epigallocatechin Gallate, Curcumin, and Resveratrol: From Dietary Sources to Human MicroRNA Modulation. Molecules 25.

Emiliano Rodríguez Mega. Colombia Latin America's embrace of an unproven COVID treatment is hindering drug trials. October 2020. Available from: https://www.nature.com/articles/ d41586-020-02958-2 (Acessed: 11 Novemeber, 2020).

Colunga Biancatelli, R. M. L., Berrill, M., Catravas, J. D. and Marik, P. E. (2020) Quercetin and Vitamin C: An Experimental, Synergistic Therapy for the Prevention and Treatment of SARS-CoV-2 Related Disease (COVID-19). Frontiers in Immunology 11, 1451.

Coronavirus a Tarde. Ministério da saúde avalia distribuir kit Covid de graça Sptember 2020. Available at: https: //coronavirus.atarde.com.br/ministerio-da-saude-avali a-distribuir-kit-covid-de-graca/ (Cited: 11 November, 2020).

Coomes, E. A. and Haghbayan, H. (2020) Favipiravir, an antiviral for COVID-19? Journal of Antimicrobial Chemotherapy 75, 2013-2014. COVID-19 Treatment. 2020. Available at: https://c19study.com/.

COVID-19 Treatment Guidelines. 2020. Available at: https://www. covid19treatmentguidelines.nih.gov/ (Accessed: 25 November, 2020).

Dabbagh-Bazarbachi, H., Clergeaud, G., Quesada, I. M., Ortiz, M., O'Sullivan, C. K. and Fernández-Larrea, J. B. (2014) Zinc ionophore activity of quercetin and epigallocatechin-gallate: from Hepa 1-6 cells to a liposome model. Journal of Agricultural and Food Chemistry 62, 8085-8093.

Deftereos, S. G., Giannopoulos, G., Vrachatis, D. A., Siasos, G. D., Giotaki, S. G., Gargalianos, P., Metallidis, S., Sianos, G., Baltagiannis, S., Panagopoulos, P., Dolianitis, K., Randou, E., Syrigos, K., Kotanidou, A., Koulouris, N. G., Milionis, H., Sipsas, N., Gogos, C., Tsoukalas, G., Olympios, C. D., Tsagalou, E., Migdalis, I., Gerakari, S., Angelidis, C., Alexopoulos, D., Davlouros, P., Hahalis, G., Kanonidis, I., Katritsis, D., Kolettis, T., Manolis, A. S., Michalis, L., Naka, K. K., Pyrgakis, V. N., Toutouzas, K. P., Triposkiadis, F., Tsioufis, K., Vavouranakis, E., Martinèz-Dolz, L., Reimers, B., Stefanini, G. G., Cleman, M., Goudevenos, J., Tsiodras, S., Tousoulis, D., Iliodromitis, E., Mehran, R., Dangas, G. and Stefanadis, C. (2020) Effect of Colchicine vs Standard Care on Cardiac and Inflammatory Biomarkers and Clinical Outcomes in Patients Hospitalized With Coronavirus Disease 2019: The GRECCO-19 Randomized Clinical Trial. JAMA Network Open 3, e2013136.

Derosa, G., Maffioli, P., D'Angelo, A. and Di Pierro, F. (2020) A role for quercetin in coronavirus disease 2019 (COVID-19). Phytotherapy Research 10.1002/ptr.6887. Online ahead of print.

Derwand, R. and Scholz, M. (2020) Does zinc supplementation enhance the clinical efficacy of chloroquine/hydroxychloroquine to win today's battle against COVID-19? Medical Hypotheses 142, 109815.

Derwand, R., Scholz, M. and Zelenko, V. (2020) COVID-19 outpatients: early risk-stratified treatment with zinc plus low-dose hydroxychloroquine and azithromycin: a retrospective case series study. International Journal of Antimicrobial Agents 56, 106214.

Diario oficial del bicentenario. Modifican el Documento Técnico: Prevención, Diagnóstico y Tratamiento de personas afectadas por COVID-19 en el Perú . Available from https://busquedas.elperuano.pe/normaslegales/modific an-el-documento-tecnico-prevencion-diagnostico-y-tr-res olucion-ministerial-n-270-2020-minsa-1866159-4/ (Acessed November 11, 2020).

Elsaid, O., McCullough, P. A., Tecson, K. M., Williams, R. S. and Yoon, A. (2020) Ventricular Fibrillation Storm in Coronavirus 2019. American Journal of Cardiology 135, 177-180.

Entrenas Castillo, M., Entrenas Costa, L. M., Vaquero Barrios, J. M., Alcalá Díaz, J. F., López Miranda, J., Bouillon, R. and Quesada Gomez, J. M. (2020) "Effect of calcifediol treatment and best available therapy versus best available therapy on intensive care unit admission and mortality among patients hospitalized for COVID-19: A pilot randomized clinical study". The Journal of Steroid Biochemistry and Molecular Biology 203, 105751.

Fan, L., Jiang, S., Yang, X., Wang, Z. and Yang, C. (2020) COVID-19 Drug Treatment in China. Current Pharmacology Reports, 1-9.

Felix, T. (2020) Nigeria goes on with hydroxychloroquine clinical trials. Anadolu Agency. Available at: https://www.aa.com.tr/en/afr ica/nigeria-goes-on-withhydroxychloroquine-clinical-trials/ 1854814 (Accessed: 19 August, 2020).

Fram, G., Wang, D. D., Malette, K., Villablanca, P., Kang, G., So, K., Basir, M. B., Khan, A., McKinnon, J. E., Zervos, M. and O'Neill, W. W. (2020) Cardiac Complications Attributed to Hydroxychloroquine: A systematic review of the Literature Pre-COVID-19. Current Cardiology Reviews.

Gendrot, M., Andreani, J., Jardot, P., Hutter, S., Delandre, O., Boxberger, M., Mosnier, J., Le Bideau, M., Duflot, I., Fonta, I., Rolland, C., Bogreau, H., La Scola, B. and Pradines, B. (2020) In Vitro Antiviral Activity of Doxycycline against SARS-CoV-2. Molecules 25.

Centers for Disease Control and Prevention. Available at: 
https://www.cdc.gov/coronavirus/2019-ncov/covid-dat a/ccovidview/05152020/covid-like-illness.html (Accessed: 03 July, 2020).

Gérard, A., Romani, S., Fresse, A., Viard, D., Parassol, N., Granvuillemin, A., Chouchana, L., Rocher, F. and Drici, M. D. (2020) "Off-label" use of hydroxychloroquine, azithromycin, lopinavir-ritonavir and chloroquine in COVID-19: A survey of cardiac adverse drug reactions by the French Network of Pharmacovigilance Centers. Thérapie 75, 371-379.

Glatthaar-Saalmüller, B., Mair, K. H. and Saalmüller, A. (2017) Antiviral activity of aspirin against RNA viruses of the respiratory tract-an in vitro study. Influenza and Other Respiratory Viruses 11, 85-92.

Gopalakrishnan, A., Mossaid, A., Lo, K. B., Vasudevan, V., McCullough, P. A. and Rangaswami, J. (2020) Fulminant Acute Kidney Injury in a Young Patient with Novel Coronavirus 2019. CardioRenal Medicine 10, 217-222.

Gorial, F., Mashhadani, S., Sayaly, H.M., Dakhil, B.D., AlMashhadani, M., Aljabory, A.M., Avvas, H.M., Ghanim, M. and Rasheed, J. (2020) Effectiveness of Ivermectin as add-on Therapy in COVID-19 Management (Pilot Trial). MedRxiv, printed online.

Gupta, A., Kalantar-Zadeh, K. and Reddy, S. T. (2020a) Ramatroban as a Novel Immunotherapy for COVID-19. Journal of Molecular and Genetic Medicine.

Gupta, S., Coca, S. G., Chan, L., Melamed, M. L., Brenner, S. K., Hayek, S. S., Sutherland, A., Puri, S., Srivastava, A., Leonberg-Yoo, A., Shehata, A. M., Flythe, J. E., Rashidi, A., Schenck, E. J., Goyal, N., Hedayati, S. S., Dy, R., Bansal, A., Athavale, A., Nguyen, H. B., Vijayan, A., Charytan, D. M., Schulze, C. E., Joo, M. J., Friedman, A. N., Zhang, J., Sosa, M. A., Judd, E., Velez, J. C. Q., Mallappallil, M., Redfern, R. E., Bansal, A. D., Neyra, J. A., Liu, K. D., Renaghan, A. D., Christov, M., Molnar, M. Z., Sharma, S., Kamal, O., Boateng, J. O., Short, S. A. P., Admon, A. J., Sise, M. E., Wang, W., Parikh, C. R. and Leaf, D. E. (2020a) AKI Treated with Renal Replacement Therapy in Critically Ill Patients with COVID-19. Journal of the American Society of Nephrology.

Gupta, S., Hayek, S. S., Wang, W., Chan, L., Mathews, K. S., Melamed, M. L., Brenner, S. K., Leonberg-Yoo, A., Schenck, E. J., Radbel, J., Reiser, J., Bansal, A., Srivastava, A., Zhou, Y., Sutherland, A., Green, A., Shehata, A. M., Goyal, N., Vijayan, A., Velez, J. C. Q., Shaefi, S., Parikh, C. R., Arunthamakun, J., Athavale, A. M., Friedman, A. N., Short, S. A. P., Kibbelaar, Z. A., Abu Omar, S., Admon, A. J., Donnelly, J. P., Gershengorn, H. B., Hernán, M. A., Semler, M. W. and Leaf, D. E. (2020b) Factors Associated With Death in Critically Ill Patients With Coronavirus Disease 2019 in the US. JAMA Internal Medicine 180, 1-12.

Han, H., Ma, Q., Li, C., Liu, R., Zhao, L., Wang, W., Zhang, P., Liu, X., Gao, G., Liu, F., Jiang, Y., Cheng, X., Zhu, C. and Xia, Y. (2020) Profiling serum cytokines in COVID-19 patients reveals IL-6 and IL-
10 are disease severity predictors. Emerging Microbes \& Infections 9 1123-1130.

Heidary, F. and Gharebaghi, R. (2020) Ivermectin: a systematic review from antiviral effects to COVID-19 complementary regimen. The Journal of Antibiotics 73, 593-602.

Hong, K. S., Jang, J. G., Hur, J., Lee, J. H., Kim, H. N., Lee, W. and Ahn, J. H. (2020) Early Hydroxychloroquine Administration for Rapid Severe Acute Respiratory Syndrome Coronavirus 2 Eradication. Journal of Infection and Chemotherapy 52, 396-402.

Horby, P., Lim, W. S., Emberson, J. R., Mafham, M., Bell, J. L., Linsell, L., Staplin, N., Brightling, C., Ustianowski, A., Elmahi, E., Prudon, B., Green, C., Felton, T., Chadwick, D., Rege, K., Fegan, C., Chappell, L. C., Faust, S. N., Jaki, T., Jeffery, K., Montgomery, A., Rowan, K., Juszczak, E., Baillie, J. K., Haynes, R. and Landray, M. J. (2020) Dexamethasone in Hospitalized Patients with Covid-19 - Preliminary Report. New England Journal of Medicine.

Hsiang, S., Allen, D., Annan-Phan, S., Bell, K., Bolliger, I., Chong, T., Druckenmiller, H., Huang, L. Y., Hultgren, A., Krasovich, E., Lau, P., Lee, J., Rolf, E., Tseng, J. and Wu, T. (2020) The effect of large-scale anti-contagion policies on the COVID-19 pandemic. Nature 584, 262 267.

Huang, H. D., Jneid, H., Aziz, M., Ravi, V., Sharma, P. S., Larsen, T., Chatterjee, N., Saour, B., Aziz, Z., Nayak, H., Trohman, R. G. and Krishnan, K. (2020) Safety and Effectiveness of Hydroxychloroquine and Azithromycin Combination Therapy for Treatment of Hospitalized Patients with COVID-19: A Propensity-Matched Study. Cardiology and Therapy 9, 523-534.

Huaxia. Senegal Roundup: Senegal to continue to treat COVID19 patients with anti-malaria drugs: expert. XINHUANET. Available at: http://www.xinhuanet.com/english/2020-06/07/c 139119593.htm.

Isaac K. Ghana, Kenya approve the use of Chloroquine to treat COVID-19 patients. Taylor and Francis group. 2020. Available at: https://africafeeds.com/2020/04/01/ghana-kenya-appro ve-use-of-chloroquine-to-treat-covid-19-patients/ (Accessed: 10 November, 2020).

Ivashchenko, A. A., Dmitriev, K. A., Vostokova, N. V., Azarova, V. N., Blinow, A. A., Egorova, A. N., Gordeev, I. G., Ilin, A. P., Karapetian, R. N., Kravchenko, D. V., Lomakin, N. V., Merkulova, E. A., Papazova, N. A., Pavlikova, E. P., Savchuk, N. P., Simakina, E. N., Sitdekov, T. A., Smolyarchuk, E. A., Tikhomolova, E. G., Yakubova, E. V. and Ivachtchenko, A. V. (2020) AVIFAVIR for Treatment of Patients with Moderate COVID-19: Interim Results of a Phase II/III Multicenter Randomized Clinical Trial. Clinical Infectious Diseases.

Izzedine, H., Jhaveri, K. D. and Perazella, M. A. (2020) COVID-19 therapeutic options for patients with kidney disease. Kidney International 97, 1297-1298. 
Jefferson, T., Spencer, E. A., Brassey, J. and Heneghan, C. (2020) SARSCoV-2 and the Role of Orofecal Transmission: Evidence Brief. In: Analysis of the Transmission Dynamics of COVID-19: An Open Evidence Review. The Centre for Evidence-Based Medicine. Available at: https://www.cebm.net/covid-19/sars-cov-2-orofeca l-transmission/.

Katharine C. EXCLUSIVE: SA to roll out chloroquine to tackle coronavirus. South African Broadcasting Corporation. 2020. Available from https://www.businesslive.co.za/fm/features/2020-03-27-s a-to-roll-out-chloroquine-to-tackle-coronavirus/ (Accessed: 19 August, 2020).

Khan, M. S. I., Khan, M. S. I., Debnath, C. R., Nath, P. N., Mahtab, M. A., Nabeka, H., Matsuda, S. and Akbar, S. M. F. (2020) Ivermectin Treatment May Improve the Prognosis of Patients With COVID-19. Archivos de Bronconeumología 56, 828-830.

Kolilekas, L., Loverdos, K., Giannakaki, S., Vlassi, L., Levounets, A., Zervas, E. and Gaga, M. (2020) Can steroids reverse the severe COVID-19 induced "cytokine storm"? Journal of Medical Virology 92, 2866-2869.

Lagier, J. C., Million, M., Gautret, P., Colson, P., Cortaredona, S., GiraudGatineau, A., Honoré, S., Gaubert, J. Y., Fournier, P. E., TissotDupont, H., Chabrière, E., Stein, A., Deharo, J. C., Fenollar, F., Rolain, J. M., Obadia, Y., Jacquier, A., La Scola, B., Brouqui, P., Drancourt, M., Parola, P. and Raoult, D. (2020) Outcomes of 3,737 COVID-19 patients treated with hydroxychloroquine/azithromycin and other regimens in Marseille, France: A retrospective analysis. Travel Medicine and Infectious Disease 36, 101791.

Li, J., Zhang, C., Wu, Z., Wang, G. and Zhao, H. (2020) The Mechanism and Clinical Outcome of patients with Corona Virus Disease 2019 Whose Nucleic Acid Test has changed from negative to positive, and the therapeutic efficacy of Favipiravir: A structured summary of a study protocol for a randomised controlled trial. Trials 21, 488.

Liu, F., Zhu, Y., Zhang, J., Li, Y. and Peng, Z. (2020) Intravenous highdose vitamin $C$ for the treatment of severe COVID-19: study protocol for a multicentre randomised controlled trial. BMJ Open 10, 039519 .

Malek, A. E., Granwehr, B. P. and Kontoyiannis, D. P. (2020) Doxycycline as a potential partner of COVID-19 therapies. IDCases 21, e00864.

Masiá, M., Fernández-González, M., García, J. A., Padilla, S. and Gutiérrez, F. (2020) Lack of detrimental effect of corticosteroids on antibody responses to SARS-CoV-2 and viral clearance in patients hospitalized with COVID-19. Journal of Infection.

McCullough, P. A., Eidt, J., Rangaswami, J., Lerma, E., Tumlin, J., Wheelan, K., Katz, N., Lepor, N. E., Vijay, K., Soman, S., Singh, B., McCullough, S. P., McCullough, H. B., Palazzuoli, A., Ruocco, G. M. and Ronco, C. (2020a) Urgent need for individual mobile phone and institutional reporting of at home, hospitalized, and intensive care unit cases of SARS-CoV-2 (COVID-19) infection. Reviews in Cardiovascular Medicine 21, 1-7.

McCullough, P. A., Kelly, R. J., Ruocco, G., Lerma, E., Tumlin, J., Wheelan, K. R., Katz, N., Lepor, N. E., Vijay, K., Carter, H., Singh, B., McCullough, S. P., Bhambi, B. K., Palazzuoli, A., De Ferrari, G. M., Milligan, G. P., Safder, T., Tecson, K. M., Wang, D. D., McKinnon, J. E., O'Neill, W. W., Zervos, M. and Risch, H. A. (2020b) Pathophysiological Basis and Rationale for Early Outpatient Treatment of SARSCoV-2 (COVID-19) Infection. The American Journal of Medicine 134, $16-22$.

McFadyen, J. D., Stevens, H. and Peter, K. (2020) The Emerging Threat of (Micro)Thrombosis in COVID-19 and Its Therapeutic Implications. Circulation Research 127, 571-587.

Mega, E. R. (2020) Latin America's embrace of an unproven COVID treatment is hindering drug trials. Nature 586, 481-482.

Melikov, A. K., Ai, Z. T. and Markov, D. G. (2020) Intermittent occupancy combined with ventilation: An efficient strategy for the reduction of airborne transmission indoors. Science of the Total Environment 744, 140908.

Meltzer, D. O., Best, T. J., Zhang, H., Vokes, T., Arora, V. and Solway, J. (2020) Association of Vitamin D Status and Other Clinical Characteristics With COVID-19 Test Results. JAMA Network Open 3, e2019722.

Mestre-Gómez, B., Lorente-Ramos, R. M., Rogado, J., Franco-Moreno, A., Obispo, B., Salazar-Chiriboga, D., Saez-Vaquero, T., TorresMacho, J., Abad-Motos, A., Cortina-Camarero, C., Such-Diaz, A.,
Ruiz-Velasco, E., Churruca-Sarasqueta, J. and Muñoz-Rivas, N. (2020) Incidence of pulmonary embolism in non-critically ill COVID-19 patients. Predicting factors for a challenging diagnosis. Journal of Thrombosis and Thrombolysis, 1-7.

Mikami, T., Miyashita, H., Yamada, T., Harrington, M., Steinberg, D., Dunn, A. and Siau, E. (2020) Risk Factors for Mortality in Patients with COVID-19 in New York City. Journal of General Internal Medicine, $1-10$.

Million, M., Lagier, J. C., Gautret, P., Colson, P., Fournier, P. E., Amrane, S., Hocquart, M., Mailhe, M., Esteves-Vieira, V., Doudier, B., Aubry, C., Correard, F., Giraud-Gatineau, A., Roussel, Y., Berenger, C., Cassir, N., Seng, P., Zandotti, C., Dhiver, C., Ravaux, I., Tomei, C., Eldin, C., Tissot-Dupont, H., Honoré, S., Stein, A., Jacquier, A., Deharo, J. C., Chabrière, E., Levasseur, A., Fenollar, F., Rolain, J. M., Obadia, Y., Brouqui, P., Drancourt, M., La Scola, B., Parola, P. and Raoult, D. (2020) Early treatment of COVID-19 patients with hydroxychloroquine and azithromycin: A retrospective analysis of 1061 cases in Marseille, France. Travel Medicine and Infectious Disease 35, 101738.

Ministério da Saúde. Acesse o Plano Nacional de Operacionalização da Vacina contra a Covid-19. Available at: https://www.gov.br/sau de/pt-br (Cited: 11 November, 2020).

Mohhamad, D. (2020) Mohhamad D Egypt uses chloroquine in treating COVID-19 patients: minister. Egypt Today staff. Available at:https://www.egypttoday.com/Article/1/83104/Egypt-u ses-chloroquine-in-treating-COVID-19-patients-Minister (Accessed: 11 November, 2020).

Moores, L. K., Tritschler, T., Brosnahan, S., Carrier, M., Collen, J. F., Doerschug, K., Holley, A. B., Jimenez, D., Le Gal, G., Rali, P. and Wells, P. (2020) Prevention, Diagnosis, and Treatment of VTE in Patients With Coronavirus Disease 2019: CHEST Guideline and Expert Panel Report. Chest 158, 1143-1163.

Mussa, K. (2020) Morocco continues the use of Chloroquine despite controversy. The North Africa Post. Available at: https://northafricapost.com/41247-morocco-continues-u se-of-chloroquine-despite-controversy.html (Accessed: November, 2020).

National Institutes of Health. (2020a) NIH begins clinical trial of hydroxychloroquine and azithromycin to treat COVID19. National Institutes of Health, Available at: https //www.nih.gov/news-events/news-releases/nih-begins-clini cal-trial-hydroxychloroquine-azithromycin-treat-covid-19 (Accessed: 03 July, 2020).

National Institutes of Health. (2020b) BULLETIN-NIH Clinical trial evaluating hydroxychloroquine and azithromycin for COVID-19 closes early. National Institutes of Health, Available at: https: //www.niaid.nih.gov/news-events/bulletin-nih-clinical-trial - evaluating-hydroxychloroquine-and-azithromycin-covid-19 (Accessed: 03 July, 2020).

Nunez, A. C., Gutierrez, T., Cervantes, J. M. L. and Juarez, M. (2020). Therapeutic Efficacy of Ivermectin as an Adjuvant in the Treatment of Patients with COVID-19. International Journal of Innovative Science and Research Technology, 5(7), 211-215

Nussbaumer-Streit, B., Mayr, V., Dobrescu, A. I., Chapman, A., Persad, E., Klerings, I., Wagner, G., Siebert, U., Christof, C., Zachariah, C. and Gartlehner, G. (2020) Quarantine alone or in combination with other public health measures to control COVID-19: a rapid review. Cochrane Database of Systematic Reviews 4, Cd013574.

Pacheco, G. (2020) Estos son los medicamentos que se prueban para combatir el covid-19. Available at: https://www.milenio.com/ci encia-y-salud/medicamentos-para-coronavirus-a-prueba-c ontra-el-covid-19 (Acessed: 11 November, 2020).

Palazzuoli, A., Ruberto, F., De Ferrari, G. M., Forleo, G., Secco, G. G., Ruocco, G. M., D'Ascenzo, F., Mojoli, F., Monticone, S., Paggi, A., Vicenzi, M., Corcione, S., Palazzo, A. G., Landolina, M., Taravelli, E., Tavazzi, G., Blasi, F., Mancone, M., Birtolo, L. I., Alessandri, F., Infusino, F., Pugliese, F., Fedele, F., De Rosa, F. G., Emmett, M., Schussler, J. M., McCullough, P. A. and Tecson, K. M. (2020) Inpatient Mortality According to Level of Respiratory Support Received for Severe Acute Respiratory Syndrome Coronavirus 2 (Coronavirus Dis- 
ease 2019) Infection: A Prospective Multicenter Study. Critical Care Explorations 2, e0220.

Pani, A., Lauriola, M., Romandini, A. and Scaglione, F. (2020) Macrolides and viral infections: focus on azithromycin in COVID-19 pathology. International Journal of Antimicrobial Agents 56, 106053.

Pereira, M., Dantas Damascena, A., Galvão Azevedo, L. M., de Almeida Oliveira, T. and da Mota Santana, J. (2020) Vitamin D deficiency aggravates COVID-19: systematic review and meta-analysis. Critical Reviews in Food Science and Nutrition, 1-9.

Pilkington, V., Pepperrell, T. and Hill, A. (2020) A review of the safety of favipiravir - a potential treatment in the COVID-19 pandemic? Journal of Virus Eradication 6, 45-51.

Pormohammad, A., Monych, N. K. and Turner, R. J. (2020) Zinc and SARS-CoV-2: A molecular modeling study of $\mathrm{Zn}$ interactions with RNA-dependent RNA-polymerase and 3C-like proteinase enzymes. International Journal of Molecular Medicine.

Price-Haywood, E. G., Burton, J., Fort, D. and Seoane, L. (2020) Hospitalization and Mortality among Black Patients and White Patients with Covid-19. The New England Journal of Medicine 382, 2534-2543.

Prodromos, C. and Rumschlag, T. (2020) Hydroxychloroquine is effective, and consistently so when provided early, for COVID-19: a systematic review. New Microbes and New Infections 38, 100776.

Prodromos, C. C., Rumschlag, T. and Perchyk, T. (2020) Hydroxychloroquine is protective to the heart, not harmful: a systematic review. New Microbes and New Infections 37, 100747.

Rahman, M. A., Iqbal, S., Islam, M. A., Niaz, M. K., Hussain, T. and Siddiquee, T. (2020) Comparison of viral clearance between ivermectin with doxycycline and hydroxychloroquine with azithromycin in COVID-19 patients. Journal of Bangladesh College of Physicians and Surgeons 38, 5-9.

Rahman, M. T. and Idid, S. Z. (2020) Can Zn Be a Critical Element in COVID-19 Treatment? Biological Trace Element Research, 1-9.

Rajter, J. C., Sherman, M. S., Fatteh, N., Vogel, F., Sacks, J. and Rajter, J. J. (2020) Use of Ivermectin Is Associated With Lower Mortality in Hospitalized Patients With Coronavirus Disease 2019: The ICON Study. Chest.

Regeneron Pharmaceuticals, Inc. Fact sheet for health care providers emergency use authorization (eua) of casirivimab and imdevimab. In: Regeneron Pharmaceuticals, Inc. Available at: https://www.fda.gov/ media/143892/download.

Rhodes, A., Evans, L. E., Alhazzani, W., Levy, M. M., Antonelli, M., Ferrer, R., Kumar, A., Sevransky, J. E., Sprung, C. L., Nunnally, M. E., Rochwerg, B., Rubenfeld, G. D., Angus, D. C., Annane, D., Beale, R. J., Bellinghan, G. J., Bernard, G. R., Chiche, J. D., Coopersmith, C., De Backer, D. P., French, C. J., Fujishima, S., Gerlach, H., Hidalgo, J. L., Hollenberg, S. M., Jones, A. E., Karnad, D. R., Kleinpell, R. M., Koh, Y., Lisboa, T. C., Machado, F. R., Marini, J. J., Marshall, J. C., Mazuski, J. E., McIntyre, L. A., McLean, A. S., Mehta, S., Moreno, R. P., Myburgh, J., Navalesi, P., Nishida, O., Osborn, T. M., Perner, A., Plunkett, C. M., Ranieri, M., Schorr, C. A., Seckel, M. A., Seymour, C. W., Shieh, L., Shukri, K. A., Simpson, S. Q., Singer, M., Thompson, B. T., Townsend, S. R., Van der Poll, T., Vincent, J. L., Wiersinga, W. J., Zimmerman, J. L. and Dellinger, R. P. (2017) Surviving Sepsis Campaign: International Guidelines for Management of Sepsis and Septic Shock: 2016. Intensive Care Medicine 43, 304-377.

Risch, H. A. (2020) Early Outpatient Treatment of Symptomatic, HighRisk COVID-19 Patients That Should Be Ramped Up Immediately as Key to the Pandemic Crisis. American Journal of Epidemiology 189, 1218-1226.

Rosenberg, E. S., Dufort, E. M., Udo, T., Wilberschied, L. A., Kumar, J., Tesoriero, J., Weinberg, P., Kirkwood, J., Muse, A., DeHovitz, J., Blog, D. S., Hutton, B., Holtgrave, D. R. and Zucker, H. A. (2020) Association of Treatment With Hydroxychloroquine or Azithromycin With In-Hospital Mortality in Patients With COVID-19 in New York State. Journal of the American Medical Association 323, 2493-2502.

Ruocco, G., McCullough, P. A., Tecson, K. M., Mancone, M., De Ferrari, G. M., D'Ascenzo, F., De Rosa, F. G., Paggi, A., Forleo, G., Secco, G. G., Pistis, G., Monticone, S., Vicenzi, M., Rota, I., Blasi, F., Pugliese, F., Fedele, F. and Palazzuoli, A. (2020) Mortality Risk Assessment Using CHA(2)DS(2)-VASc Scores in Patients Hospitalized With Coronavirus Disease 2019 Infection. The American Journal of Cardiology
137, 111-117.

Santos-Sánchez, N. F. and Salas-Coronado, R. (2020) Origin, structural characteristics, prevention measures, diagnosis and potential drugs to prevent and COVID-19. Medwave 20, e8037.

Schrezenmeier, E. and Dörner, T. (2020) Mechanisms of action of hydroxychloroquine and chloroquine: implications for rheumatology. Nature Reviews Rheumatology 16, 155-166.

Schmith, V. D., Zhou, J. J. and Lohmer, L. R. L. (2020) The approved dose of ivermectin alone is not the ideal dose for the treatment of COVID19. Clinical Pharmacology \& Therapeutics 108, 762-765.

Sharma, P., Reddy, P. K. and Kumar, B. (2020) Trace Element Zinc, a Nature's Gift to Fight Unprecedented Global Pandemic COVID-19. Biol Trace Elem Res, 1-9.

Sheng, W. H. (2020) Interim Guidelines for Clinical Management of SARS-CoV-2 Infection (5th edition). Available at: https://fightcov id.edu.tw/cdc-guidelines/clinical-management (Acessede: 11 November, 2020).

Shojaei, A. and Salari, P. (2020) COVID-19 and off label use of drugs: an ethical viewpoint. Daru 28, 789-793.

Singh, A. K., Majumdar, S., Singh, R. and Misra, A. (2020) Role of corticosteroid in the management of COVID-19: A systemic review and a Clinician's perspective. Diabetes and Metabolic Syndrome 14, 971978.

Singhania, N., Bansal, S., Nimmatoori, D. P., Ejaz, A. A., McCullough, P. A. and Singhania, G. (2020) Current Overview on Hypercoagulability in COVID-19. American Journal of Cardiovascular Drugs 20, 393-403.

Sodhi, M. and Etminan, M. (2020) Therapeutic Potential for Tetracyclines in the Treatment of COVID-19. Pharmacotherapy 40, 487-488.

Sterne, J. A. C., Murthy, S., Diaz, J. V., Slutsky, A. S., Villar, J., Angus, D C., Annane, D., Azevedo, L. C. P., Berwanger, O., Cavalcanti, A. B. Dequin, P. F., Du, B., Emberson, J., Fisher, D., Giraudeau, B., Gordon, A. C., Granholm, A., Green, C., Haynes, R., Heming, N., Higgins, J. P. T., Horby, P., Jüni, P., Landray, M. J., Le Gouge, A., Leclerc, M., Lim, W. S., Machado, F. R., McArthur, C., Meziani, F., Møller, M. H., Perner, A., Petersen, M. W., Savovic, J., Tomazini, B., Veiga, V. C., Webb, S. and Marshall, J. C. (2020) Association Between Administration of Systemic Corticosteroids and Mortality Among Critically Ill Patients With COVID-19: A Meta-analysis. Journal of the American Medical Association 324, 1330-1341.

Szente Fonseca, S. N., de Queiroz Sousa, A., Wolkoff, A. G., Moreira, M. S., Pinto, B. C., Valente Takeda, C. F., Rebouças, E., Vasconcellos Abdon, A. P., Nascimento, A. L. A. and Risch, H. A. (2020) Risk of hospitalization for Covid-19 outpatients treated with various drug regimens in Brazil: Comparative analysis. Travel Medicine and Infectious Disease 38, 101906.

Tang, N., Bai, H., Chen, X., Gong, J., Li, D. and Sun, Z. (2020) Anticoagulant treatment is associated with decreased mortality in severe coronavirus disease 2019 patients with coagulopathy. Journal of Thrombosis and Haemostasis 18, 1094-1099.

te Velthuis, A. J., van den Worm, S. H., Sims, A. C., Baric, R. S., Snijder, E. J. and van Hemert, M. J. (2010) $\mathrm{Zn}(2+)$ inhibits coronavirus and arterivirus RNA polymerase activity in vitro and zinc ionophores block the replication of these viruses in cell culture. PLoS Pathogens 6, e1001176.

The Independent. (2020) Museveni P Uganda records good results in treating COVID with hydroxychloroquine, chloroquine. Available at https://www.independent.co.ug/uganda-records-good-resul ts-treating-COVID-with-hydroxychloroquine-chloroquine/ (Accessed: 19 August, 2020).

Trial Site News. Ivermectin usage accelerates while the need for data is real: how about an ivermectin registry? Trial Site News. Available at: https://www.trialsitenews.com/ivermectin-usage-accelerat es-while-the-need-for-data-is-real-how-about-an-ivermecti n-registry/ (Cited: 11 November, 2020).

Turshudzhyan, A. (2020) Anticoagulation Options for Coronavirus Disease 2019 (COVID-19)-Induced Coagulopathy. Cureus 12, e8150.

Vaduganathan, M., van Meijgaard, J., Mehra, M. R., Joseph, J., O'Donnell, C. J. and Warraich, H. J. (2020) Prescription Fill Patterns for Commonly Used Drugs During the COVID-19 Pandemic in the United States. Journal of the American Medical Association 323, 2524-2526. 
Vahidy, F. S., Drews, A. L., Masud, F. N., Schwartz, R. L., Askary, B. B., Boom, M. L. and Phillips, R. A. (2020) Characteristics and Outcomes of COVID-19 Patients During Initial Peak and Resurgence in the Houston Metropolitan Area. Journal of the American Medical Association 324, 998-1000.

Vora, A., Arora, V. K., Behera, D. and Tripathy, S. K. (2020) White paper on Ivermectin as a potential therapy for COVID-19. Indian $J$ Tuberc 67, 448-451.

Westafer, L. M., Elia, T., Medarametla, V. and Lagu, T. (2020) A Transdisciplinary COVID-19 Early Respiratory Intervention Protocol: An Implementation Story. Journal of Hospital Medicine 15, 372-374.

World Health Organisation (WHO). (2020) COVID-19 Studies from the World Health Organization Database. Available at: https://clinical trials.gov/ct2/who_table.

World Health Organization. (2020) R\&D blueprint and COVID-19. Available at: https://www.who.int/blueprint/priority-diseases/ke y-action/novel-coronavirus/en/ (Accessed: 25 March, 2020).

Xiao, J., Shiu, E. Y. C., Gao, H., Wong, J. Y., Fong, M. W., Ryu, S. and Cowling, B. J. (2020) Nonpharmaceutical Measures for Pandemic Influenza in Nonhealthcare Settings-Personal Protective and Environmental Measures. Emerging Infectious Diseases 26, 967-975.

Xu, X. K., Liu, X. F., Wu, Y., Ali, S. T., Du, Z., Bosetti, P., Lau, E. H.
Y., Cowling, B. J. and Wang, L. (2020) Reconstruction of Transmission Pairs for novel Coronavirus Disease 2019 (COVID-19) in mainland China: Estimation of Super-spreading Events, Serial Interval, and Hazard of Infection. Clinical Infectious Diseases.

Yamakawa, M., Kuno, T., Mikami, T., Takagi, H. and Gronseth, G. (2020) Clinical Characteristics of Stroke with COVID-19: A Systematic Review and Meta-Analysis. Journal of Stroke \& Cerebrovascular Diseases 29, 105288

Yang, B. Y., Barnard, L. M., Emert, J. M., Drucker, C., Schwarcz, L., Counts, C. R., Murphy, D. L., Guan, S., Kume, K., Rodriquez, K., Jacinto, T., May, S., Sayre, M. R., Seattle Fire Department, Seattle, Washington and Rea, T. (2020) Clinical characteristics of patients with coronavirus disease 2019 (COVID-19) receiving emergency medical services in King County, Washington. Jama Network Open 3, e2014549.

Zhang, J., McCullough, P. A. and Tecson, K. M. (2020a) Vitamin D deficiency in association with endothelial dysfunction: Implications for patients with COVID-19. Reviews in Cardiovascular Medicine 21, 339344.

Zhang, J., Tecson, K. M. and McCullough, P. A. (2020b) Endothelial dysfunction contributes to COVID-19-associated vascular inflammation and coagulopathy. Reviews in Cardiovascular Medicine 21, 315-319. 